\title{
Inhibition Effect of Different Corrosion Inhibitors on Steel Bars Corrosion and Improvement Effect After Double Doped
}

\author{
Minghui Jiang', Meiyan Hang ${ }^{1}$, Yubing Yang ${ }^{1}{ }^{*}$, Teng Cheng ${ }^{1}$, Hao Wang ${ }^{1}$, Gangming Zhou ${ }^{2}$ \\ ${ }^{1}$ School of Civil Engineering, Inner Mongolia University of Science and Technology, Baotou, China \\ ${ }^{2}$ Beijing Tieke Shougang Rail Technology Co., Ltd, Beijing, China \\ Email address: \\ 358898234@126.com (Yubing Yang) \\ ${ }^{*}$ Corresponding author
}

To cite this article:

Minghui Jiang, Meiyan Hang, Yubing Yang, Teng Cheng, Hao Wang, Gangming Zhou. Inhibition Effect of Different Corrosion Inhibitors on Steel Bars Corrosion and Improvement Effect After Double Doped. Science Journal of Chemistry. Vol. 9, No. 4, 2021 , pp. 105-112. doi: $10.11648 / j . s j c .20210904 .13$

Received: August 12, 2021; Accepted: August 26, 2021; Published: August 31, 2021

\begin{abstract}
Reinforced concrete structures are easily corroded in the Salt Lake areas of China, especially in harsh environmental circumstance, such as freezing-thawing cycles, wetting-dry, et al, thus causing a lot of damage problems (concrete deterioration and steel bars corrosion). This research investigation was a research study which was to solve the corrosion problem of reinforced concrete structures under the chloride environmental circumstance through the electrochemical performance and mechanical properties test of the reinforced mortar specimens, the effect of single or compound doping of two organic and two inorganic corrosion inhibitors to the electrode potential, electrochemical impedance spectroscopy and mechanical properties of the reinforced mortar were investigated. The experimental conclusion demonstrated that the organic or inorganic corrosion inhibitors after single and compound doping showed some degree influence on the electrode potential and mechanical properties of the reinforced mortar specimens. Meanwhile, when the ratio of triethanolamine (TEA):triisopropanolamine (TIPA) was 7:3, sodium monofluorophosphate (MFP):sodium molybdate was 5:5, the compressive strength and flexural strength of mortar after curing for 28 days were greater than $90 \%$, it indicated that these proportions showed the best corrosion resistance performance of steel bars. Therefore, these proportions of corrosion inhibitors could be used in reinforced concrete structures. The significant was that these results could provide theoretical guidance and technical basis for the study of corrosion damage of reinforced concrete structures in the future.
\end{abstract}

Keywords: Corrosion, Reinforced Concrete Structures, Corrosion Inhibitors, Electrochemical Performance

\section{Introduction}

Reinforced concrete structures are extensively used in civil engineering structures such as architecture, bridge, and ocean engineering because of its ascendant material properties. Nonetheless, reinforced concrete structures easily occur corrosion damage on the circumstance of alkaline land, resulting in a large number of durability problems. It's reported that corrosion-induced deterioration structures and infrastructure account for 2.5 trillion dollars per annum globally [1]. Which not only cause significant economic losses, but also bring great hidden trouble [2, 3]. Therefore, it's a significant science and technology issue in the world to enhance the durability and prolong service life of reinforced concrete structures [4]. Research shows that the reinforced corrosion is one of crucial factors affecting the durability of reinforced concrete, chloride ions penetration is the most direct cause of reinforced corrosion [5, 6]. Moreover, chloride induced reinforcing concrete corrosion is a significant issue of people's attention [7-13]. Therefore, it is extremely significant to search rust-inhibiting substances that hinder chloride ions absorbed on the surface of steel bar or inhibit occurred the electrochemical reaction on the surface of steel bar in erosive environment, reducing or even eliminating the corrosion of 
reinforced concrete [14, 15].

The scientific community is working along several lines of research to provide some solutions to solve all corrosion problems, including decreasing the water binder ratio of concrete, using improved materials, using the corrosion protective coatings, using the sulfur-resistant cement, and incorporating corrosion inhibitors [16-19]. According to these researches, the first four methods have some of shortcomings, whereas corrosion inhibitors may be a good alternative to other protection methods or classical repair methods because of its lower cost and easy application [20]. Therefore, using a number of different types of corrosion inhibitors can effectively inhibit the reinforced concrete structures suffering from corrosion [21, 22]. A number of inhibitors were developed, including various amines, alkanolamines, their salts with organic and inorganic acids and emulsified mixtures of esters, alcohols and amines during since 1990 [23]. The main method of using corrosion inhibitors are: added to fresh concrete as an admixture, applied on the hardened concrete surface, and added to repair mortars or be added to repair mortars or used as a surface treatment on the reinforcement bars before concreting, etc [19].

The purpose of this study of this research was to aimed to investigate the influence of single or compound doping of organic and inorganic corrosion inhibitors to the electrode potential of the steel bar and the mechanical properties of the mortar, verifying the inhibition performance of corrosion inhibitors. The organic corrosion inhibitors of TEA and TIPA, the inorganic corrosion inhibitors of MFP and sodium molybdate were selected to study in this research. Firstly, TEA and TIPA were single incorporated into mortar with the content of $0.5 \%, 1.0 \%, 1.5 \%, 2.0 \%, 3.0 \%$, respectively, and their mixing ratio of 3:7, 5:5, 7:3, respectively. Meanwhile, MFP and sodium molybdate were incorporated into mortar with the same ratio. Then the electrode potential and mechanical properties of the reinforced mortar were analyzed to confirm the effect of two organic and inorganic corrosion inhibitors on the reinforced mortar. Finally, the best organic and inorganic corrosion inhibitors of inhibition performance would be selected to provide theoretical guidance and technical support for solving the durability problem of the reinforced concrete structures.

\section{Experimental Scheme}

\subsection{Materials and Mix Proportion}

Ordinary Portland cement with strength grade of 42.5 produced by Inner Mongolia Mengxi Co. Ltd was used in this research. The physical and mechanical properties of cement were presented in Table 1. The fineness and mud content of natural river sand were 2.5 and $2.7 \%$, respectively. This research used the sodium chloride solution with a concentration of $4 \%$ as the mortar mixing water. It was confirmed after study that the proportion of mortar was as follows: water-binder ratio was 0.5 , cement-sand ratio was $1: 3$. The ratio of ordinary portland cement:sand:water was 280:828:160. In order to reduce the problem of the steel bar corrosion damage, the two organic and inorganic corrosion inhibitors were incorporated to the mortar with the content of two organic and inorganic corrosion inhibitors was $0 \%, 0.5 \%, 1.0 \%, 1.5 \%, 2.0 \%, 2.5 \%$, $3.0 \%$, respectively, including TEA and TIPA, MFP and sodium molybdate. The anticorrosion performance and mechanical properties of two organic and inorganic corrosion inhibitors might be different, therefore, they were compounded in different proportion in order to investigated whether they could better improved the anticorrosion performance and mechanical properties of the mortar.

Table 1. The physical and mechanical properties of cement.

\begin{tabular}{|c|c|c|c|c|c|c|c|}
\hline \multirow{2}{*}{ Cement } & \multirow{2}{*}{$\begin{array}{l}\text { Fineness }(45 \mu \mathrm{m}) \\
/ \%\end{array}$} & \multirow{2}{*}{$\begin{array}{l}\text { Standard } \\
\text { consistence /\% }\end{array}$} & \multirow{2}{*}{$\begin{array}{l}\text { Specific surface } \\
\text { area } / \mathbf{m}^{2} / \mathbf{k g}\end{array}$} & \multicolumn{2}{|c|}{ Setting time / min } & \multicolumn{2}{|c|}{ Flexural and compressive strength / MPa } \\
\hline & & & & Initial set & Final set & 3 days & 28 days \\
\hline $\mathrm{P} \cdot \mathrm{O} 42.5$ & 4.5 & 27.5 & 386 & 135 & 225 & $5.0 / 35.4$ & $8.6 / 49.5$ \\
\hline
\end{tabular}

\subsection{Experimental Methods}

In this research, the Class I building steel bars with length of $100 \mathrm{~mm}$ and diameter of $7 \mathrm{~mm}$ were utilized. In addition, 180\# sand paper was used to polish the surface of steel bars to a surface roughness of $1.6 \mu \mathrm{m}$, used acetone to exscind its surface degrease and washed with distilled water. Mortar specimens of dimension $30 \mathrm{~mm} \times 30 \mathrm{~mm} \times 95 \mathrm{~mm}$ was made by testing mixing ratio, both ends of test mold contained concave holes with a diameter of $7.5 \mathrm{~mm}$ to fix steel bars. Firstly, the wire was welded at both ends of test molds and the polished steel bar were embedded into the test molds, then carefully poured the mortar into molds and used the cement slurry to block its both ends, the specimens were cured in the room temperature for 24 hours and demolded. The Steel bar's electrode potential text was followed JT/T537-2018 "Corrosion inhibitor for reinforcing steel in concrete". PS-6 steel bar corrosion instrument was used for testing the steel bar electrode potential. The mortar-steel specimens were used as the electrochemical measurement materials. On the back of steel bars was welded the wire, polished to $800 \#$ with metallographic sand paper, then put it into the PVC sleeve. The other surface was sealed with epoxy resin except the front surface and $10 \mathrm{~mm}$ thick mortar was poured into the outside steel bar of working surface.

The mechanical properties of mortar specimens were measured on the basis of T0506-2005 standard for test method of mortar strength. Two organic and two inorganic corrosion inhibitors were single or combined incorporated at different proportions compounding in mortar, then mortar specimens with the size of $40 \mathrm{~mm} \times 40 \mathrm{~mm} \times 160 \mathrm{~mm}$ were made for measuring these flexural strength and compressive strength in curing for 7 days and 28 days, to 
explore whether they could improve the mechanical properties of the reinforced mortar after single or compound addition.

\section{Results and Analysis}

\subsection{Organic Corrosion Inhibitors}

\subsubsection{Electrode Potential and Mechanical Properties of Single Incorporated Corrosion Inhibitor}

The electrode potential influence curve of two corrosion inhibitors for steel bar after curing for 28 days is depicted in Figure 1. Figure 1(a) shows that the electrode potential of the steel bars showed a downward trend and the steel bar occurred corrosion under the circumstance of no corrosion inhibitor. When the mixing amount of TEA was lower than $1.5 \%$, the electrode potential of steel bar electrode was different degree of decrease after $30 \mathrm{~min}$ of energizing, and steel bar existed the risk of corrosion; when the mixing amount was range from $1.5 \%$ to $2.0 \%$, the electrode potential of steel bar electrode maintained in the passive state, it indicated that this amount of corrosion inhibitor was better effect on the corrosion of steel bar. The reason for the was that TEA contained hydroxyl, the corrosion rate of the steel bars would gradually decrease due to the activity of hydroxyl greater than that of chloride ions [24]; when its mixing content was greater than $2.5 \%$, the electrode potential of steel bars was reduced obviously and the risk of steel bar corrosion was improved. The result showed that the mixing content of TEA at the dosage of $1.5 \% \sim 2 \%$ was good inhibition performance and the effect was not changed significantly over time. Figure 1(b) shows that the electrode potential of each curve was rapidly increased and it could maintain over $800 \mathrm{mV}$ after $6 \mathrm{~min}$ of electrifying, the electrode potential of the specimen of each mixing amount was stationary after continuing $30 \mathrm{~min}$ of electrifying, it showed that the steel bar showed an significant anticorrosion effect under the mixing amount range from $0 \%$ to $3 \%$. TIPA was a strong dispersion and it could enhance absorption effect after it incorporated in concrete inner. Therefore, it was a better inhibition performance in a larger incorporating range [25].

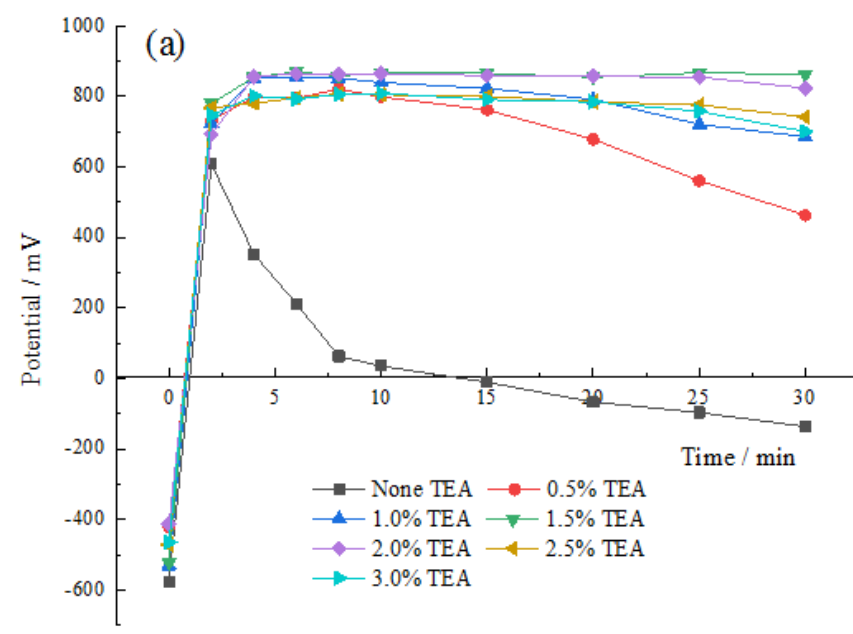

Figure 1. (a) The influence of TEA on electrode potential of the steel bars; (b) The influence of TIPA on electrode potential of the steel bars.

The fluidity, flexural strength and compressive strength of mortar specimens after additive respectively $0 \sim 3 \%$ corrosion inhibitors in 7 days and 28 days are depicted in Figure 2. Figure 2(a) shows that after incorporating organic corrosion inhibitors, the fluidity of mortar changed in different degree; with increasing the amount of TEA, the fluidity of mortar increased at first and then decreased, while TIPA was basically no influence, it indicated that the organic corrosion inhibitor showed little effect on the fresh mortar state. Figure 2(b) shows that the flexural strength of mortar specimens after curing for 7 days was a low amplitude scope after adding corrosion inhibitor, it was a significantly rising amplitude after adding TEA, it indicated that TEA could promote cement hydration and enhance the early mortar strength [26]. In addition, the flexural strength of two groups of corrosion inhibitor after curing for 28 days was approximately same to reference group, the comparison indicated that two kinds of corrosion inhibitors showed little influence on the flexural strength. Figure 2(c) shows that the compressive strength of mortar after curing for 7 days adding TEA was slightly promoted compared with the group without incorporating corrosion inhibitor and it's improved more obvious in this group. It's hydration products growth by TEA and increased the compactness of cement hydration products, thus promoting the compressive strength of mortar [27], TIPA could also accelerate the hydration of cement, and generated C-S-H gel, blocked in the internal of specimens, then improved the density of specimens, finally improved the strength of specimens [28]. Therefore, the lifting strength of TEA was more significant. The compressive strength of mortar after curing for 28 days showed a slight decreased after incorporating different kinds of corrosion inhibitors, then it was greatly decreased with increasing the amount of TEA and decreased to less than $80 \%$, on the contrary, TIPA was little influence. 

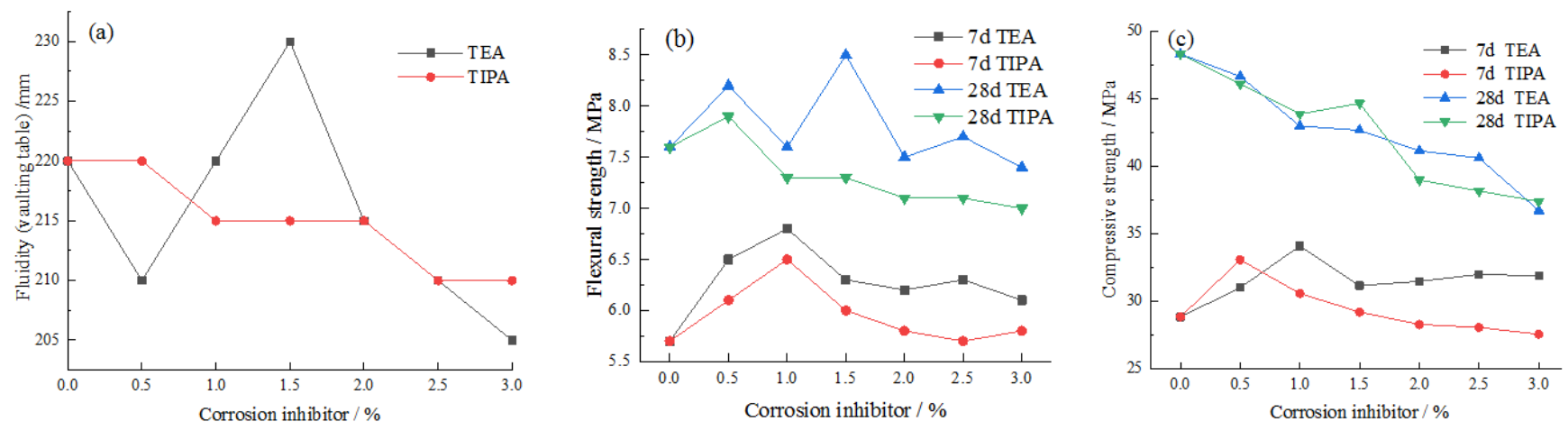

Figure 2. (a) The fluidity of mortar specimens; (b) The flexural strength of mortar specimens in different ages; (c) The compressive strength of mortar specimens in different ages.

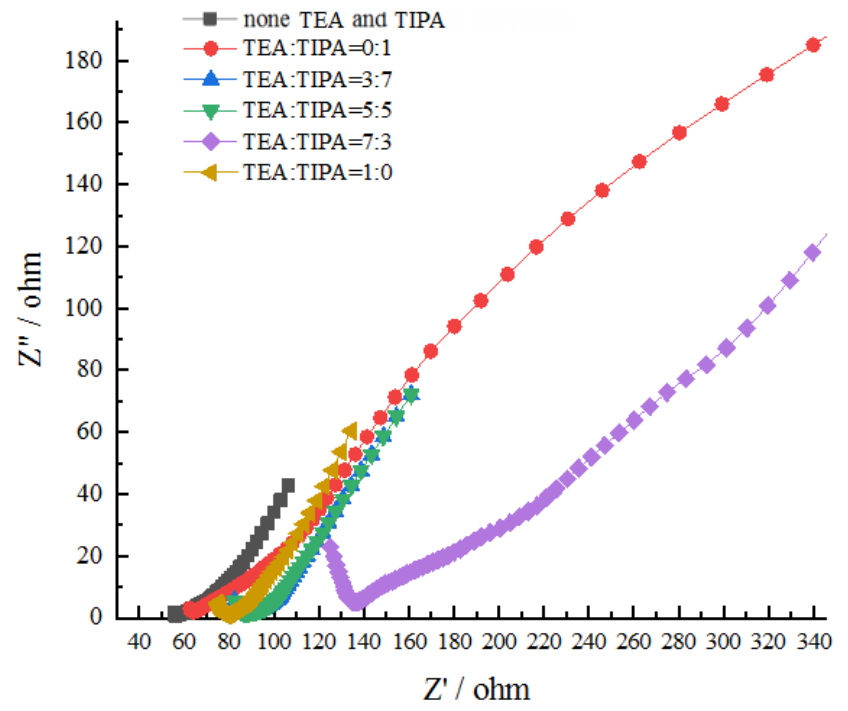

Figure 3. The impedance spectrum spectroscopy of the reinforced bar specimens after incorporating TEA and TIPA.

\subsubsection{Electrochemical Impedance Spectroscopy and Mechanical Properties of Compounded Corrosion Inhibitor}

In this research, TEA and TIPA were combined incorporated at different proportion compounding in mortar in order to explore the effect of the impedance spectrum and mechanical properties of the reinforced mortar. The impedance spectrum of the reinforced bar specimens after incorporating TEA and TIPA in different proportions is depicted in Figure 3. At high frequency band, the capacitance arc of reference group was sharply contracted and the steel bars were corrosion tendency, while the capacitance arc of adding different proportion corrosion inhibitors was increased, it indicated that different proportion corrosion inhibitors were better inhibitory effect on reinforcement corrosion. At low frequency band, the radius of capacitance arc increased slightly compared with standard group, while corrosion inhibitors after compounding improve in a certain extent for reinforcement corrosion. It can be seen from the Figure 2 that the capacitance arc of compound doped corrosion inhibitors group was more significantly increased than single doped corrosion inhibitor group and standard group at high frequency band and its radius was maximum when the ratio of TEA:TIPA was 7:3, the comparison indicated that this ratio of corrosion inhibitors was the best inhibition performance, the reason for this was that TEA and TIPA contained the $\mathrm{N}$ atom, showed high activity, the electrostatic effect of $\mathrm{N}$ atom and the spatial common effect of molecular structure also affected the change of adjacent position or spatial distance of molecule, they would form the passivation film on the surface of the steel bar, TEA and TIPA worked together, and increased the radius of capacitance arc of steel bars, finally improved the corrosion resistance of steel bars [29].

The flexural strength and compressive strength of mortar specimens with compounding TEA and TIPA in different proportions are enumerated in Table 2. Compared with the incorporated ratio of more than half of mortar, although the flexural strength of mortar after compounding corrosion inhibitors still was decreased in some extent, the flexural strength ratio of mortar was more than $90 \%$, it indicated that the effect of the corrosion inhibitor on the flexural strength of mortar could be controlled on smaller levels. By experiment, it could be shown from the results of the electrochemical impedance test of the mortar-reinforced specimens and the mechanical properties of mortar, the inhibition performance of mortar was the best when the ratio of TEA:TIPA was 7:3. Meanwhile, the compressive strength ratio of mortar after curing for 28 days reaches $97.76 \%$ and the flexural strength ratio of mortar after curing for 28 days was $97.59 \%$, it demonstrated that this proportion could be used as corrosion inhibitor to reduce the corrosion damage problem of the reinforced concrete structures. 

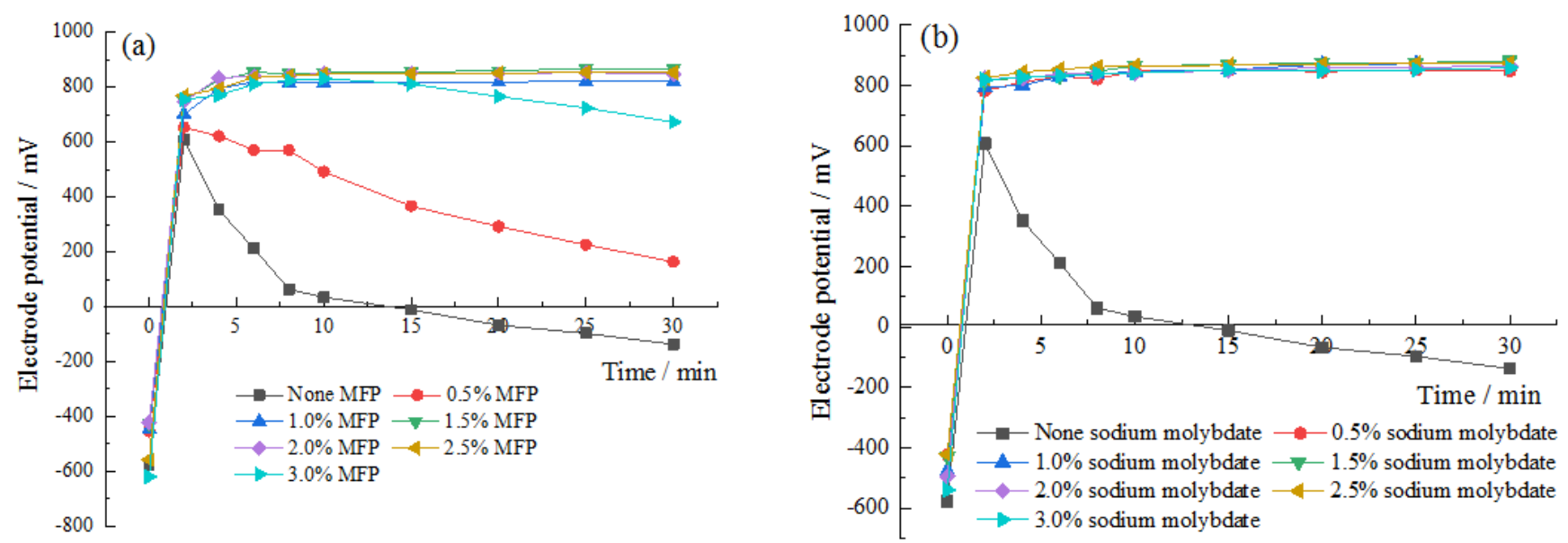

Figure 4. (a) The electrode potential of the reinforced bar specimens after incorporating MFP; (b) The electrode potential of the reinforced bar specimens after incorporating sodium molybdate.

Table 2. The flexural strength and compressive strength of mortar specimens with organic corrosion inhibitors.

\begin{tabular}{lllllllll}
\hline \multirow{2}{*}{ TEA:TIPA } & \multicolumn{2}{l}{ Flexural strength / MPa } & \multicolumn{2}{l}{ Flexural strength ratio /\% } & \multicolumn{2}{c}{ Compressive strength / MPa } & \multicolumn{2}{c}{ Compressive Strength ratio/\% } \\
\cline { 2 - 9 } & $\mathbf{7 d}$ & $\mathbf{2 8 d}$ & $\mathbf{7 d}$ & $\mathbf{2 8 d}$ & $\mathbf{7 d}$ & $\mathbf{2 8 d}$ & $\mathbf{7 d}$ & $\mathbf{2 8 d}$ \\
\hline Vacuity group & $\mathbf{7 . 0}$ & $\mathbf{8 . 3}$ & - & - & $\mathbf{2 9 . 0}$ & $\mathbf{4 9 . 1}$ & - & - \\
\hline $3: 7$ & 6.1 & 7.0 & 87.14 & 84.34 & 25.1 & 41.9 & 86.55 & 85.33 \\
$5: 5$ & 6.7 & 7.7 & 95.71 & 92.77 & 27.0 & 46.4 & 93.10 & 94.50 \\
$7: 3$ & 7.0 & 8.1 & 101.41 & 97.59 & 31.9 & 48.0 & 110.00 & 97.76 \\
\hline
\end{tabular}

\subsection{Inorganic Corrosion Inhibitors}

\subsubsection{Electrode Potential and Mechanical Properties of Single Incorporated Corrosion Inhibitor}

The electrode potential influence curve of two inorganic corrosion inhibitors for steel bar after curing for 28 days is shown in Figure 4. Figure 4(a) shows that the electrode potential of the steel bar was different degree of increasing after incorporating MFP. When the mixing amount was range from $1.5 \%$ to $2.0 \%$, the electrode potential of steel bar basically maintained unchanged after $30 \mathrm{~min}$ of energizing and it's in a passive state, it indicated that this amount of corrosion inhibitor could effectively inhibit the corrosion of steel bar. The reason for this was that MEP could react with calcium hydroxide to generate apatite, the apatite would accumulate in the porous network, thus preventing the penetration of aggressive ions entered the surface of the steel bars, therefore, it could improve the corrosion resistance of steel bars, the reaction equations are as shown in equations (1) [30]. when its mixing content was $3 \%$, the electrode potential of steel bars decreased slightly, moreover, it indicated that its inhibition on the corrosion of steel bar was reduced and the steel bar exhibited the risk of corrosion. Figure 4(b) shows that the electrode potential of the reinforced mortar did not decrease after $30 \mathrm{~min}$ of energizing, it demonstrated that sodium molybdate was a better inhibition performance when its mixing amount was between $0.5 \%$ and $3 \%$. The reason for this was that sodium molybdate could absorb the positively charged metal on the surface of steel bars to form a passive film, and exhibited good corrosion inhibition performance [31].
$5 \mathrm{Ca}(\mathrm{OH})_{2}+3 \mathrm{Na}_{2} \mathrm{PO}_{3} \mathrm{~F}+3 \mathrm{H}_{2} \mathrm{O} \rightarrow \mathrm{Ca}_{5}\left(\mathrm{PO}_{4}\right)_{3} \mathrm{~F}+2 \mathrm{NaF}+4 \mathrm{NaOH}+6 \mathrm{H}_{2} \mathrm{O}(1)$

The fluidity, flexural strength and compressive strength of mortar specimens after additive respectively $0 \sim 3 \%$ corrosion inhibitor in 7 days and 28 days are depicted in Figure 5. After incorporating inorganic corrosion inhibitors, the fluidity of mortar changed in different degree; after incorporating MFP, the fluidity of mortar decreased greatly at first and then increased slightly, this indicated that MFP displayed certain retarding effects, so it could reduce the fluidity of mortar. In addition, the fluidity of mortar was consistent with the reference group when its dosage was $3 \%$; the fluidity of mortar reduced significantly with increasing the amount of sodium molybdate. It can be seen that the former showed little influence on the mortar state, but the latter would be a greater impact. Besides, the flexural strength and compressive strength of mortar after curing for 7 days and 28 days increased slightly when the mixing amount of sodium molybdate was below $2 \%$, it might be that sodium molybdate decreased the fluidity of mortar, and then improved the strength of mortar; when the mixing amount was greater than $2 \%$, the flexural strength of mortar after curing for 7 days was basically consistent with the reference group, the compressive strength of mortar was improved in different degree, the reason for this was that sodium molybdate could promote the hydration of cement, generated a lot of hydration products, and from dense structures, thus improve the strength of specimens; when the mixing amount was less than $1.5 \%$, the compressive strength of mortar after curing for 28 days was basically unchanged; when the mixing amount was more than $1.5 \%$, the strength of the mortar decreases slightly. After incorporating MFP, the flexural strength and compressive 
strength of mortar after curing for 7 days and 28 days decreased significantly, the maximum flexural strength and compressive

strength ratio were decreased less than $90 \%$.
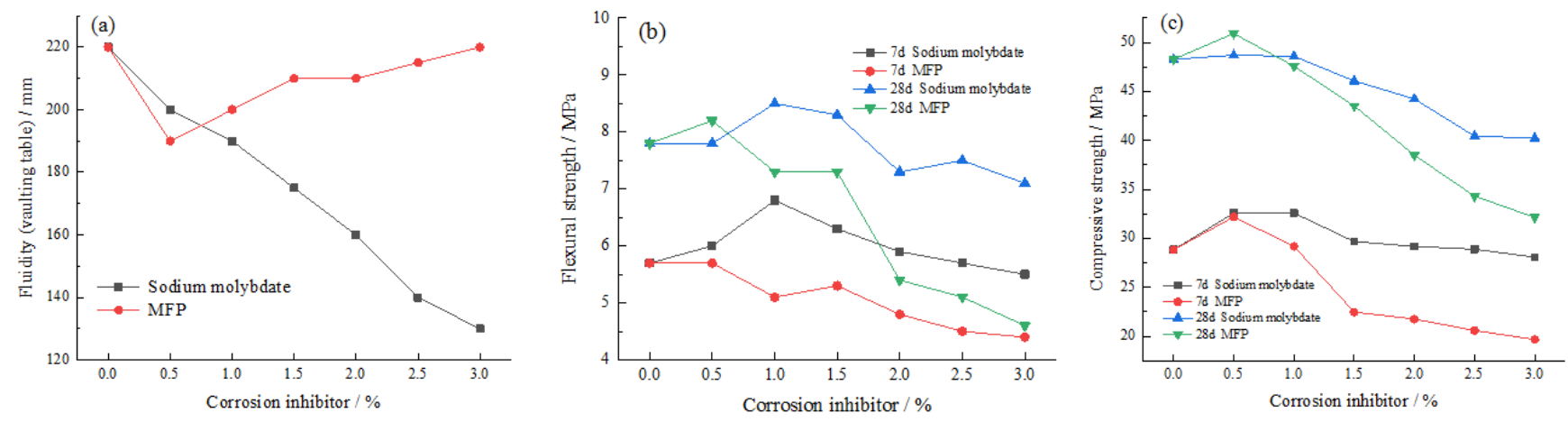

Figure 5. (a) The fluidity of mortar specimens; (b) The flexural strength of mortar specimens in different ages; (c) The compressive strength of mortar specimens in different ages.

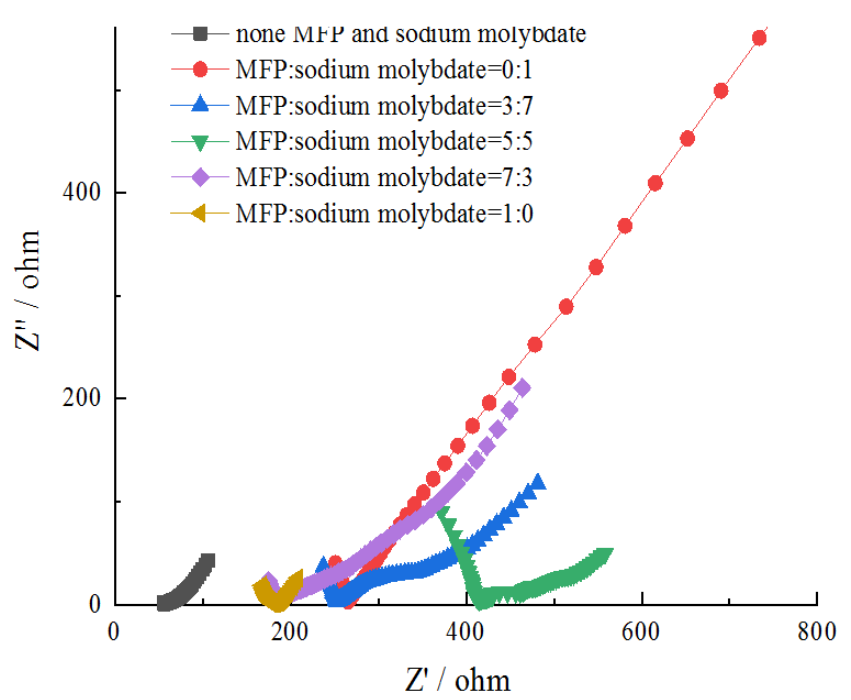

Figure 6. The impedance spectrum of the reinforced bar specimens after incorporating TEA and TIPA.

\subsubsection{Electrochemical Impedance and Mechanical \\ Properties of Compounded Corrosion inhibitor}

The impedance spectrum of the reinforced bar specimens after incorporating MFP and sodium molybdate in different proportions is depicted in Figure 6. Compared with the reference group, the capacitance arc radius of steel bar at high frequency band was increased in different degree. Meanwhile, the inorganic corrosion inhibitor group's capacitance arc radius was larger than the organic corrosion inhibitors group, it's contributed by inorganic corrosion inhibitors played a significant role in inhibiting by affecting the electrochemical process of the corrosion of steel bar, because MFP and sodium molybdate could work together to absorb the $\mathrm{Fe}^{2+}$ ions on the surface of steel bars, then form passivation film $\left(\gamma-\mathrm{Fe}_{2} \mathrm{O}_{3}\right)$ on the surface of steel bar, thus improving the corrosion resistance of steel bars, therefore, the capacitance arc radius of steel bar would increase after incorporating the inorganic corrosion inhibitor. It can be seen from the impedance spectrum of the reinforced bar after adding different proportions of the inorganic corrosion inhibitor, when the ratio of MFP and sodium molybdate were 5:5, its radius was maximum, it demonstrated that this proportion of corrosion inhibitors showed the best inhibition performance and it could be used as corrosion inhibitor in actual engineering.

The flexural strength and compressive strength of mortar specimens with MFP and sodium molybdate in different proportions are enumerated in Table 3. Compared with the single-doped MFP, the compressive strength of mortar after compounded two corrosion inhibitors was obviously improved. The compressive strength ratio could meet the requirement when the mixing ratio was $5: 5$ or $7: 3$, it demonstrated that the effect of the two proportions on the mechanical properties of mortar could be reduced to a control range. The result showed that the inhibition performance showed the best when their mixing ratio was 5:5. Meanwhile, the compressive strength ratio and flexural strength ratio of mortar after curing for 28 days could achieve $94.58 \%, 93.82 \%$, respectively, it demonstrated that this proportion could be used as corrosion inhibitor, the reason for this was that both of corrosion inhibitors could accelerate the hydration of cement, generate a lot of products, block the internal pores of specimens, thus improving the density of specimens, therefore, the strength of specimens could be improved.

Table 3. The flexural strength and compressive strength of mortar specimens with inorganic corrosion inhibitors.

\begin{tabular}{llllllll}
\hline MFP:sodium & \multicolumn{2}{l}{ Flexural strength/MPa } & \multicolumn{2}{l}{ Flexural strength ratio/\% } & \multicolumn{2}{c}{ Compressive Strength/MPa } & Compressive Strength ratio/\% \\
\cline { 2 - 7 } molybdate & $\mathbf{7 d}$ & $\mathbf{2 8 d}$ & $\mathbf{7 d}$ & $\mathbf{2 8 d}$ & $\mathbf{7 d}$ & $\mathbf{2 8 d}$ & $\mathbf{\text { 28d }}$ \\
\hline Vacuity group & $\mathbf{6 . 8}$ & $\mathbf{8 . 1}$ & -- & -- & $\mathbf{2 8 . 9}$ & $\mathbf{4 8 . 0}$ & - \\
\hline $3: 7$ & 5.9 & 7.0 & 86.76 & 86.41 & 25.0 & 41.8 & 86.50 \\
$5: 5$ & 6.6 & 7.6 & 97.06 & 93.82 & 26.8 & 45.4 & 92.73 \\
$7: 3$ & 6.9 & 7.8 & 101.47 & 96.30 & 31.7 & 47.1 & 94.58 \\
\hline
\end{tabular}




\section{Conclusions}

In this research, the influence of single or compound doping of two corrosion inhibitors to the electrode potential and mechanical properties of the reinforced mortar were presented. The following conclusion could be stated:

1) The content of TEA, TIPA, MFP and sodium molybdate at the dosage of $1.5 \%$ could maintain the potential and could not decrease after 30 min of electrifying in the mortar-steel bar electrode potential test, which could effectively inhibit the corrosion of steel bars.

2) The organic corrosion inhibitors TEA and TIPA, the inorganic corrosion inhibitors MFP and sodium molybdate were slightly different the anticorrosion performance and mechanical properties of mortar after uni-doped. When the mixing amount of corrosion inhibitors was range from $1.5 \% \sim 2.0 \%$, the inhibition performance of the former was greater than the later; moreover, the compressive strength of the former was less than the later.

3) The inhibition performance of mortar was promoted by compounding corrosion inhibitors. The inhibition performance of mortar showed the best when the ratio of TEA: TIPA was 7:3, and MFP and sodium molybdate was 5:5. Meanwhile, the compressive strength and flexural strength of mortar after curing for 28 days were greater than $90 \%$, it indicated that these proportions were the best inhibition performance and they could be used as corrosion inhibitors.

\section{Data Availability Statement}

All data, models, and code generated or used during the study appear in the submitted article.

\section{Acknowledgements}

The study of this work was financially supported by the Natural Science Foundation of Inner Mongolia Province of China (grant no.2018MS0534) and Natural Science Foundation of Inner Mongolia (grant no.2018MS05034).

\section{References}

[1] NACE, International measures of prevention, application and economics of corrosion technology, NACE International, 2016.

[2] Sugama T., Carciello N. R. (2010). Corrosion protection of steel and bond durability at polyphenylene sulfide-to-anhydrous zinc phosphate interfaces [J]. Journal of Applied Polymer Science, 45 (7): 1291-1301.

[3] Alawi A., Mohammed M., Baghabra A. A. O. S., Saleh T. A., Mohammed S. (2018). Efficiency of generic and proprietary inhibitors in mitigating Corrosion of Carbon Steel in Chloride-Sulfate Environments [J]. Reproductive Science, 8 (1): 11443 .

[4] Karagöl F., Yegin Y., Polat R., Benli A. (2018). The influence of lightweight aggregate, freezing-thawing procedure and air entraining agent on freezing-thawing damage [J]. Structural Concrete, 19 (5): 1328-1340.

[5] Mehta P. K., Burrows R. W. (2001). Building durable structures in the 21 st century. Concrete International, 75 (7): 437-443.

[6] Miyagawa T. (1991). Durability design and repair of concrete structures: chloride corrosion of reinforcing steel and alkali-aggregate reaction [J]. Magazine of Concrete Research, 44: $147-147$.

[7] Asipita S. A., Ismail M., Majid M. Z. A., Majid Z. A., Abdullah C. S., Mirza J. (2014). Green Bambusa Arundinacea leaves extract as a sustainable corrosion inhibitor in steel reinforced concrete [J]. Journal of Cleaner Production, 67 (6): 139-146.

[8] Cai J., Chen C., Liu J., Liu J. (2014). Corrosion resistance of carbon steel in simulated concrete pore solution in presence of 1-dihydroxyethylamino-3-dipropylamino-2-propanol as corrosion inhibitor [J]. British Corrosion Journal, 49 (1) 66-72.

[9] Ahmad S. (2003). Reinforcement corrosion in concrete structures, its monitoring and service life prediction: a review [J]. Cement and Concrete Composites, 25 (4) 459-471.

[10] Duffó G. S., Farina S. B., Giordano C. M. (2009). Characterization of solid embeddable reference electrodes for corrosion monitoring in reinforced concrete structures [J]. Electrochimical Acta, 54 (3): 1010-1020.

[11] Dhouibi L., Triki E., Raharinaivo A. (2002). The application of electrochemical impedance spectroscopy to determine the long-term effectiveness of corrosion inhibitors for steel in concrete [J]. Cement and Concrete Composites, 24 (1): 35-43.

[12] Glass G. K., Buenfeld N. R. (2000). The influence of chloride binding on the chloride induced corrosion risk in reinforced concrete [J]. Corrosion Science, 42 (2): 329-344.

[13] Garcés P., Saura P., Zornoza E., Andrade C. (2011). Influence of $\mathrm{pH}$ on the nitrite corrosion inhibition of reinforcing steel in simulated concrete pore solution $[\mathrm{J}]$. Corrosion Science, 53 (12): 3991-4000.

[14] Chen C., Jiang L. H., Guo M. Z., Xu P., Chen L., Zha J. (2019). Effect of sulfate ions on corrosion of reinforced steel treated by DNA corrosion inhibitor in simulated concrete pore solution [J]. Construction and Building Materials, 228 (20): 116752.1-116752.8.

[15] Zhou Y., Chen C. C., Cai J. S., Liu J. Z. (2016). Corrosion Behavior of Corrosion Resistant Reinforcing Steels and Their Synergistic Corrosion Resistant Effect with Corrosion Inhibitor [J]. Journal of Building Materials 19 (02): 379-384. (In Chinese).

[16] Song J. L., Li Y. X., Xu W., Lu Y. (2019). Inexpensive and non-fluorinated superhydrophobic concrete coating for anti-icing and anti-corrosion [J]. Journal of Colloid and Interface Science, 541.

[17] Ding R., Chen S., Lv J., Zhang W., Li W. H. (2019). Study on graphene modified organic anti-corrosion coatings: A comprehensive review [J]. Journal of Alloys Compdounds, 806: 611-635. 
[18] Xia Z. B., Liu G. Z., Dong Y. Q., Zhang Y. H. (2019). Anticorrosive epoxy coatings based on polydopamine modified molybdenum disulfide [J]. Progress in Organic Coatings, 133: 154-160.

[19] Söylev T. A., Richardson M. G. (2006). Corrosion inhibitors for steel in concrete: State-of-the-art report [J]. Construction and Building Materials, 22 (4): 609-622.

[20] Al-Amoudi O. S. B., Maslehuddin M., Lashari A. N., Almusallam A. A. (2003). Effectiveness of corrosion inhibitors in contaminated concrete [J]. Cement and Concrete Composites, 25 (4): 439-449.

[21] Xu C., Jin W. L., Wang H. L., Wu H. T., Huang N., Li Z. Y., Mao J. H. (2016). Organic corrosion inhibitor of triethylenetetramine into chloride contamination concrete by eletro-injection method $[\mathrm{J}]$. Construction and Building Materials, 115.

[22] Tang Y. M., Zhang G. D., Zuo Y. (2011). The inhibition effects of several inhibitors on steel bar in acidified concrete pore solution [J]. Construction and Building Materials, 28 (1): 327-332.

[23] Qian S., Cusson D. (2004). Electrochemical evaluation of the performance of corrosion- inhibiting systems in concrete bridges [J]. Cement and Concrete Composites, 26: 217-233.

[24] Liu J. P., Chen C. C., Cai J. S., Liu J. Z., Cui G. (2013). 1,3-Bis-dibutylaminopropan-2-ol as inhibitor for reinforcement steel in chloride-contaminated simulated concrete pore solution[J]. Materials and Corrosion. 64 (12): 1075-1081.

[25] Wang J., Ma B. G., Tan H. B. (2021). Hydration and mechanical properties of cement-marble powder system incorporating triisopropanolamine $[\mathrm{J}]$. Construction and Building Materials, 266 (PB): 121068.

[26] Heinz D., Göbel M., Hilbig H., Urbonas L., Bujauskaite G. (2010). Effect of TEA on fly ash solubility and early age strength of mortar [J]. Cement and Concrete Research. 40 (3): 392-397.

[27] Katsioti M., Tsakiridis P. E., Giannatos P., Tsibouki Z., Marinos J. (2009). Characterization of various cement grinding aids and their impact on grindability and cement performance [J]. Construction and Building Materials, 23 (5): 1954-1959.

[28] Shaikh F. U. A., Supit S. W. M. (2014). Mechanical and durability properties of high volume fly ash (HVFA) concrete containing calcium carbonate $\left(\mathrm{CaCO}_{3}\right)$ nanoparticles [J]. Construction and Building Materials, 70: 309-321.

[29] Jamil H. E., Shriri A., Boulif R., Bastos C., Montemor M. F., Ferreira M. G. S. (2004) Electrochemical behaviour of amino alcohol-based inhibitors used to control corrosion of reinforcing steel $[\mathrm{J}]$. Electrochemical Acta, 49: 2753-2760.

[30] Chaussadent T., Nobel-Pujol V., Farcas F., Mabille I., Fiaud C. (2006). Effectiveness conditions of sodium monofluorophosphate as a corrosion inhibitor for concrete reinforcements [J]. Cement and Concrete Research, 36 (3): $556-561$.

[31] Li X., Deng S., Hui F. (2011). Sodium molybdate as a corrosion inhibitor for aluminium in $\mathrm{H} 3 \mathrm{PO} 4$ solution [J]. Corrosion Science, 53 (9): 2748-2753. 